\title{
Development of Glutamate Sensor for Neurotransmitter Imaging
}

\author{
Shinya Mizutani, ${ }^{1 *}$ Yuki Okumura, ${ }^{1}$ Tomoko Horio, ${ }^{1}$ \\ Tatsuya Iwata, ${ }^{1}$ Koich Okumura, ${ }^{1}$ Kazuhiro Takahashi, ${ }^{1}$ Yuji Murakami, ${ }^{1}$ \\ Fumihiro Dasai, ${ }^{1}$ Makoto Ishida, ${ }^{1}$ and Kazuaki Sawada ${ }^{1,2}$ \\ ${ }^{1}$ Toyohashi University of Technology, 1-1 Hibarigaoka, Tempaku-cho, Toyohashi, Aichi 441-8580, Japan \\ ${ }^{2}$ Electronics-Inspired Interdisciplinary Research Institute (EIIRIS), \\ 1-1 Hibarigaoka, Tempaku-cho, Toyohashi, Aichi 441-8580, Japan
}

(Received September 1, 2016; accepted December 14, 2016)

Keywords: extended-gate FET, enzyme sensor, $\mathrm{H}_{2} \mathrm{O}_{2}$, glutamate, neurotransmitter

We report an enzyme-based potentiometric glutamate sensor combined with a semiconductor device for neurotransmitter imaging, the response of which is based on the detection of the interfacial potential of a gold electrode produced by redox and enzyme reactions. First, we confirmed that the interfacial potential increased logarithmically with the increasing concentration ratio of hexacyanoferrate(III) to hexacyanoferrate(II). The proposed sensor could detect the interfacial potential change of the gold electrode with a slope of $66.1 \mathrm{mV} /$ decade. $\mathrm{H}_{2} \mathrm{O}_{2}$ and L-glutamate were detected as a function of the change in the interfacial potential of the gold electrode in the range of $0.01-1 \mathrm{mM}$. Slopes of 55.2 and $41.9 \mathrm{mV} /$ decade were obtained as the sensitivities for $\mathrm{H}_{2} \mathrm{O}_{2}$ and L-glutamate, respectively. These estimated values are larger than the theoretical value of $29.5 \mathrm{mV} /$ decade. Although the reason why the difference between the estimated value and the theoretical value occurred could not be revealed, the interfacial potential is expected to depend on some kind of reaction related to $\mathrm{H}_{2} \mathrm{O}_{2}$ concentration because the logarithmic response was obtained for $\mathrm{H}_{2} \mathrm{O}_{2}$ concentration. Therefore, the results suggested that the sensor can detect the L-glutamate concentration.

\section{Introduction}

L-Glutamate is widely known as a major neurotransmitter in mammalian brains. It has been pointed out that the spatiotemporal distribution of extrasynaptic L-glutamate concentrations in brains is an important factor in controlling neural functions. ${ }^{(1)}$ Accordingly, sensing devices that can visualize L-glutamate distribution are required.

Amperometric and potentiometric sensors for detecting $\mathrm{H}_{2} \mathrm{O}_{2}$, as well as those for detecting L-glutamate, have been studied.(2-9) Among these electrochemical biosensors, potentiometric devices are advantageous for imaging because their sensitivity essentially does not change with decreasing sensing area. In addition, potentiometric image sensors, or $\mathrm{pH}$ image sensors, have been developed to visualize the two-dimensional $\mathrm{pH}$ distribution in solutions. ${ }^{(10)}$ The sensing of several biomolecules such as adenosine triphosphate (ATP) and acetylcholine (ACh) was demonstrated using $\mathrm{pH}$ image sensors combined with enzymatic membranes. ${ }^{(11,12)}$ However, since the sensing of "Corresponding author: e-mail: mizutani-s@int.ee.tut.ac.jp http://dx.doi.org/10.18494/SAM.2017.1455 
biomolecules relies on the $\mathrm{H}^{+}$generated by enzymatic reactions, the output of the $\mathrm{pH}$ image sensor can be affected by the $\mathrm{pH}$ variations in a specimen, the ionic strength, and the buffer capacity of the solution. For this reason, development has been focused on biomolecule sensors based on $\mathrm{pH}-$ independent potentiometric sensing. ${ }^{(13)}$ In this study, a pH-independent potentiometric glutamate sensor utilizing potential changes of the gold electrode caused by a redox reaction combined with some enzymatic reactions was proposed.

\section{Materials and Methods}

\subsection{Materials}

Horseradish peroxidase (HRP), L-glutamate ( $\geq 99.0 \%)$, and ferrocenylmethyl alcohol $(\mathrm{FcMeOH})(95 \%)$ were purchased from Sigma-Aldrich Inc. HRP is an enzyme and $\mathrm{FcMeOH}$ is a metal complex, and these were used to detect $\mathrm{H}_{2} \mathrm{O}_{2}$. Sodium 4-(2-hydroxyethyl)piperazine1-ethanesulfonate (HEPES) $(\geq 99.0 \%)$ and L-glutamate oxidase were purchased from Dojindo Laboratories and Cosmo Bio Co., Ltd., respectively. A HEPES buffer solution was used as the solvent, and L-glutamate oxidase was used as a catalyst to produce $\mathrm{H}_{2} \mathrm{O}_{2}$ from L-glutamate. Ethanol (99.5\%), hydrogen peroxide (30.0\%), potassium hexacyanoferrate(II) trihydrate $(99.5 \%)$, and potassium hexacyanoferrate(III) $(99.0 \%)$ were purchased from Wako Pure Chemical Industries, Ltd. Ethanol was used to dissolve $\mathrm{FcMeOH}$, and potassium hexacyanoferrate(II) trihydrate and potassium hexacyanoferrate(III) were used in the experiment to confirm the measurement principle. The HEPES buffer solution was prepared using deionized water $\left(18.2 \mathrm{M} \Omega \cdot \mathrm{cm}\right.$ at $\left.25^{\circ} \mathrm{C}\right)$.

\subsection{Measurement principle of the concentration of L-glutamate}

L-Glutamate sensing is essentially based on the change in interfacial potential between a gold electrode and a solution. A similar study has been reported. ${ }^{(13)}$ Hydrogen peroxide $\left(\mathrm{H}_{2} \mathrm{O}_{2}\right)$ as an oxidant is generated by an enzyme reaction involving L-glutamate, as shown in

$$
\text { L-glutamate }+\mathrm{O}_{2}+\mathrm{H}_{2} \mathrm{O} \underset{\text { L-glutamate oxidase }}{\longrightarrow} \alpha \text {-ketoglutarate }+\mathrm{NH}_{3}+\mathrm{H}_{2} \mathrm{O}_{2} \text {. }
$$

$\mathrm{H}_{2} \mathrm{O}_{2}$ is converted to $\mathrm{H}_{2} \mathrm{O}$ by catalysis with $\mathrm{HRP}$; simultaneously, the oxidation of FcMeOH occurs. Equation (2) shows this chemical reaction.

$$
\mathrm{H}_{2} \mathrm{O}_{2}+2 \mathrm{H}^{+}+2 \mathrm{FcMeOH} \underset{\mathrm{HRP}}{\longrightarrow} 2 \mathrm{H}_{2} \mathrm{O}+2 \mathrm{FcMeOH}^{+}
$$

$\mathrm{FcMeOH}$ is a metal complex described with the formula $\mathrm{C}_{11} \mathrm{H}_{12} \mathrm{FeO}$. The oxidation state of iron of $\mathrm{FcMeOH}$ is +2 , and that of iron of $\mathrm{FcMeOH}^{+}$is +3 . The concentration ratio of $\mathrm{FcMeOH}$ to $\mathrm{FcMeOH}^{+}$is changed as a function of the L-glutamate concentration.

In this case, the interfacial potential of the gold electrode is determined by the equilibrium between $\mathrm{FcMeOH}$ and $\mathrm{FcMeOH}^{+}$.(13) On the other hand, from Eq. (2), the interfacial potential can also be determined by the equilibrium between $\mathrm{H}_{2} \mathrm{O}_{2}$ and $\mathrm{H}_{2} \mathrm{O}$. Therefore, the interfacial potential is described by Eqs. (3) and (4). 


$$
\begin{gathered}
E=E^{\circ \prime}-\frac{R T}{n F} \ln \frac{[\mathrm{Red}]}{[\mathrm{Ox}]}=E^{\circ \prime}+0.0591 \log \frac{\left[\mathrm{FcMeOH}^{+}\right]}{[\mathrm{FcMeOH}]} \\
E=E^{\circ \prime}+0.0295 \log \frac{\left[\mathrm{H}_{2} \mathrm{O}_{2}\right]}{\left[\mathrm{H}_{2} \mathrm{O}\right]} \quad \text { (V) }
\end{gathered}
$$

Here, $E^{\circ \prime}$ is the formal potential, $R$ is the universal gas constant, $T$ is the absolute temperature, $n$ is the number of electrons transferred in the redox reaction, and $\mathrm{F}$ is the Faraday constant. Ox and Red are the concentrations of an oxidant and a reductant, respectively. Equation (4) reveals that the relationship between the interfacial potential of the gold electrode and the $\mathrm{H}_{2} \mathrm{O}_{2}$ concentration becomes $29.5 \mathrm{mV} /$ decade. From Eqs. (1) and (4), the interfacial potential of the gold electrode is expected to increase logarithmically as the L-glutamate concentration increases. The source follower circuit detects the output $\left(V_{\text {out }}\right)$ expressed by

$$
V_{\text {out }}=E-E_{R E}+V_{\text {ref }}-V_{g s} \text {. }
$$

Here, $E$ is the interfacial potential of the gold electrode, $E_{R E}$ is the potential of the reference electrode to the solution, $V_{r e f}$ is the constant voltage applied to the reference electrode, and $V_{g s}$ is the gate-to-source voltage. $V_{g s}$ and $E_{R E}$ are constants.

\subsection{Measurement system}

Figure 1 shows a schematic of the measurement setup. It consists of a gold electrode and a source follower circuit with a metal-oxide-semiconductor field-effect transistor (MOSFET). A gold electrode with an area of $1 \times 1 \mathrm{~mm}^{2}$ was deposited on an $\mathrm{SiO}_{2} / \mathrm{Si}$ chip with an adhesion layer of titanium, as shown in Fig. 1. The titanium and gold films were deposited by sputtering, and the thicknesses of the films are about 40 and $300 \mathrm{~nm}$, respectively. The metal films were patterned by a lift-off process. Figure 2 shows a photograph of the gold electrode with the name of each part.

For the source follower circuit, either an n-channel enhancement-mode or an n-channel depletion-mode MOSFET was used. Both have a gate oxide with a thickness of about 100 $\mathrm{nm}$ grown by thermal oxidation for $150 \mathrm{~min}$ at $1000{ }^{\circ} \mathrm{C}$. In the $\mathrm{n}$-channel enhancement-mode

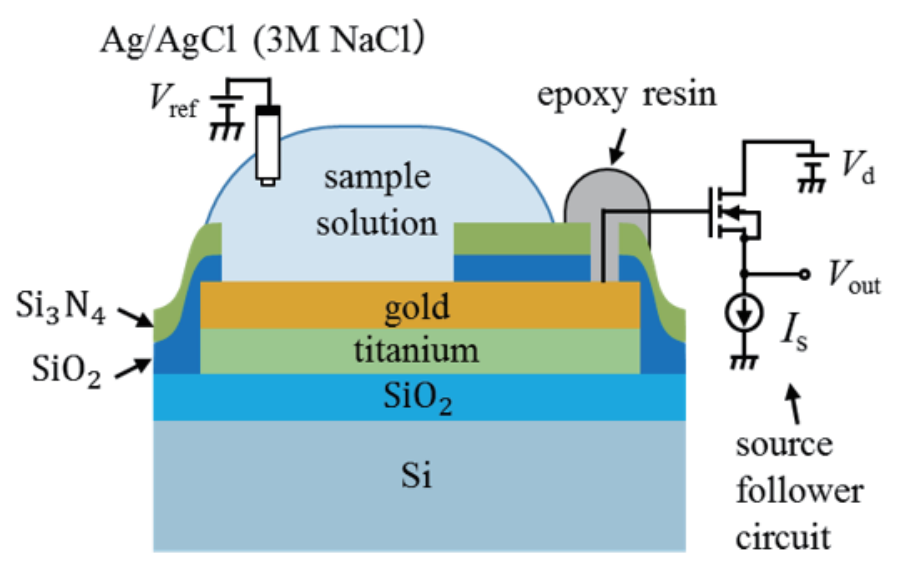

Fig. 1. (Color online) A schematic of the measurement setup. 


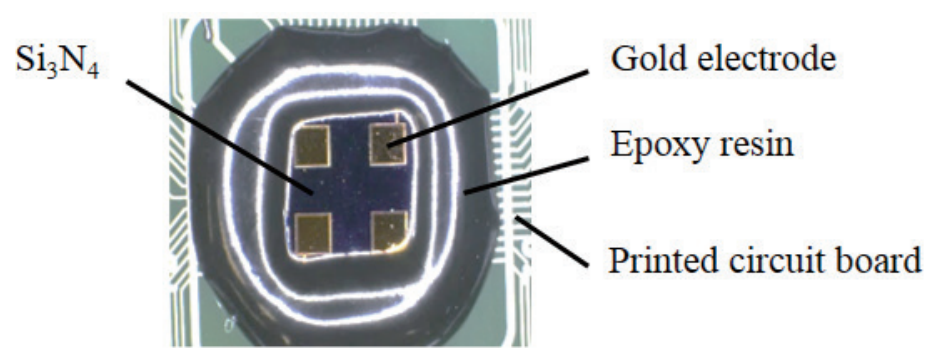

Fig. 2. (Color online) A photograph of the gold electrode. The chip size is $5 \times 5 \mathrm{~mm}^{2}$ and the area of a gold electrode is $1 \times 1 \mathrm{~mm}^{2}$.

MOSFET, the width $(W)$ and length $(L)$ of the gate are 40 and $10 \mu \mathrm{m}$, while in the n-channel depletion-mode MOSFET, $W$ and $L$ of the gate are 40 and $40 \mu \mathrm{m}$, respectively. In the n-channel depletion-mode MOSFET, the threshold voltage was controlled by $\mathrm{P}^{+}$implantation at $60 \mathrm{keV}$, and the dose was about $1.5 \times 10^{12} \mathrm{~cm}^{-2}$. The gold electrode is connected to the gate area of the MOSFET.

For the measurement, the gold electrode and an $\mathrm{Ag} / \mathrm{AgCl}$ reference electrode containing $3 \mathrm{M}$ $\mathrm{NaCl}$ solution (RE-1B, BAS Inc.) were immersed in a sample solution. The sample was put in a closed box with a piece of wet paper to reduce the evaporation of the solution. The interfacial potential of the gold electrode was measured using a source follower circuit and recorded by a semiconductor device analyzer (SDA) (B1500A, Agilent Technologies). A constant current, $I_{s}$, and constant voltages, $V_{\text {ref }}$ and $V_{d}$, were provided by the SDA, and the common ground is that of the SDA. The n-channel enhancement-mode MOSFET was used to measure the solutions of hexacyanoferrate(III) and hexacyanoferrate(II). In this case, $I_{s}=18.2 \mu \mathrm{A}, V_{\text {ref }}=2 \mathrm{~V}$, and $V_{d}$ $=4 \mathrm{~V}$. The n-channel depletion-mode MOSFET was used in the measurement of the $\mathrm{H}_{2} \mathrm{O}_{2}$ and L-glutamate solutions. In this case, $I_{s}=172.0 \mu \mathrm{A}, V_{\text {ref }}=0 \mathrm{~V}$, and $V_{d}=4 \mathrm{~V}$. All the measurements were conducted at $25^{\circ} \mathrm{C}$.

\subsection{Measurement procedure}

\subsubsection{Measurement in the solutions of hexacyanoferrate(III) and (II)}

We first measured the output for different concentration ratios of hexacyanoferrate(III) to hexacyanoferrate(II) to verify the principle of the sensor. The measurements were conducted according to Ref. 14 as follows. The sensor and a reference electrode were immersed in $100 \mu \mathrm{L}$ of the solutions of hexacyanoferrate(III) and hexacyanoferrate(II) at ratios of 1:9, 2:8, 3:7, 4:6, 5:5, 6:4, 7:3, 8:2, and 9:1. The total concentration of each solution was $10 \mathrm{mM}$, and hexacyanoferrate(III) and (II) were dissolved in $100 \mathrm{mM}$ HEPES buffer solution. The output was then measured for 5 $\min$.

\subsubsection{Measurement of $\mathrm{H}_{2} \mathrm{O}_{2}$ solutions of varying concentrations}

The gold electrode and a reference electrode were immersed in $45 \mu \mathrm{L}$ of the enzyme solution. The enzyme solution consisted of $80 \mathrm{mM}$ HEPES buffer solution, $500 \mu \mathrm{M} \mathrm{FcMeOH}$, and 0.12 units/ $\mu \mathrm{L}$ HRP. FcMeOH was dissolved in methanol before being added to the HEPES buffer solution. 
During the measurements, $5 \mu \mathrm{L}$ of $\mathrm{H}_{2} \mathrm{O}_{2}$ solution at each concentration diluted with 80 mM HEPES buffer solution was added at 10 min intervals so that the final concentrations of $\mathrm{H}_{2} \mathrm{O}_{2}$ became $0.01,0.05$, $0.1,0.5$, and $1 \mathrm{mM}$. Every $\mathrm{H}_{2} \mathrm{O}_{2}$ solution also contained $500 \mu \mathrm{M} \mathrm{FcMeOH}$.

\subsubsection{Measurement of L-glutamate solutions of varying concentrations}

The gold electrode and a reference electrode were immersed in $45 \mu \mathrm{L}$ of the enzyme solution. The enzyme solution consisted of $80 \mathrm{mM}$ HEPES, $500 \mu \mathrm{M} \mathrm{FcMeOH}, 0.12$ units $/ \mu \mathrm{L}$ HRP, and 0.028 units/ $\mu \mathrm{L}$ L-glutamate oxidase. $\mathrm{FcMeOH}$ was dissolved in methanol before being added to the HEPES solution. During the measurements, $5 \mu \mathrm{L}$ of L-glutamate solution at each concentration diluted with $80 \mathrm{mM}$ HEPES buffer solution was added at 10 min intervals so that the final concentrations of L-glutamate were $0.01,0.05,0.1,0.5$, and $1 \mathrm{mM}$. Every L-glutamate solution also contained $500 \mu \mathrm{M} \mathrm{FcMeOH}$.

\section{Results and Discussion}

\subsection{Measurement of the solution of hexacyanoferrate(III) and (II)}

Figure 3 shows the output in response to the concentration ratio of hexacyanoferrate(III) to hexacyanoferrate(II). The output increased as the concentration ratio of hexacyanoferrate(III) to hexacyanoferrate(II) increased. Here, the increase in the output means the increase in the interfacial potential because $V_{g s}$ and $E_{R E}$ are constant. The output was stable for $5 \mathrm{~min}$. Figure 4 shows the relationship between the ratio of hexacyanoferrate(III) to hexacyanoferrate(II) and the output 5 min later. The output change in each ratio of hexacyanoferrate(III) to hexacyanoferrate(II) was plotted after $5 \mathrm{~min}$. The output increased logarithmically with incremental changes in the ratio of hexacyanoferrate(III) to hexacyanoferrate(II) in the range of 1:9-9:1, and the slope of the line is $66.1 \mathrm{mV} /$ decade.

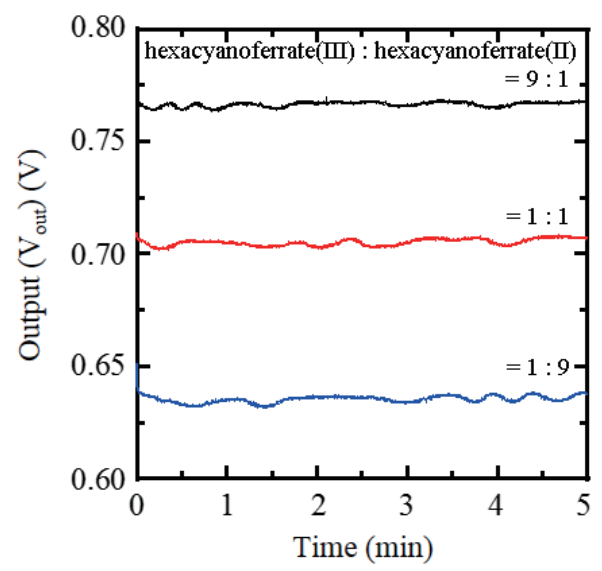

Fig. 3. (Color online) Output $\left(V_{\text {out }}\right)$ in response to the concentration ratio of hexacyanoferrate(III) to hexacyanoferrate(II).

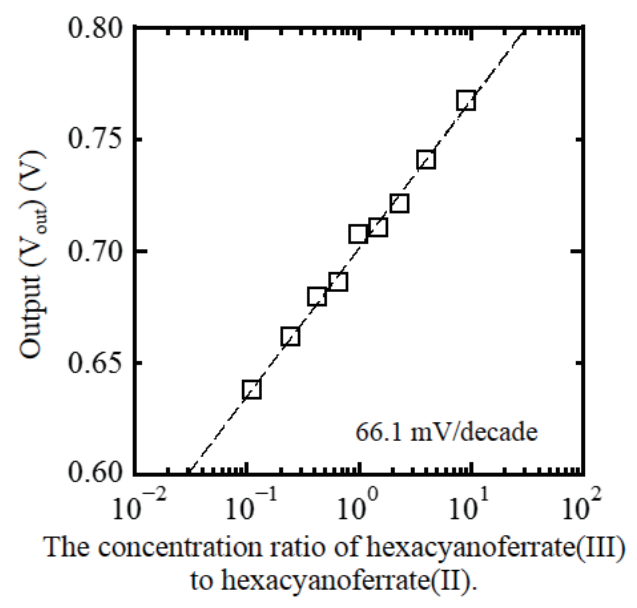

Fig. 4. Relationship between the output $\left(V_{\text {out }}\right)$ and the concentration ratio of hexacyanoferrate(III) to hexacyanoferrate(II). 
From the Nernst equation, the theoretical value is expected to be $59.1 \mathrm{mV} /$ decade, as shown in Eq. (6). ${ }^{(14)}\left[\mathrm{Fe}(\mathrm{CN})_{6}\right]^{3-}$ and $\left[\mathrm{Fe}(\mathrm{CN})_{6}\right]^{4-}$ describe the concentrations of hexacyanoferrate(III) and hexacyanoferrate(II), respectively. The results suggest that the proposed sensor can detect the interfacial potential change of the gold electrode with a slope of $66.1 \mathrm{mV} /$ decade.

$$
\begin{aligned}
E & =E^{\circ \prime}-\frac{R T}{n F} \ln \frac{[\mathrm{Red}]}{[\mathrm{Ox}]}=E^{\circ \prime}-0.0591 \log \frac{\left[\left[\mathrm{Fe}(\mathrm{CN})_{6}\right]^{4-}\right]}{\left[\left[\mathrm{Fe}(\mathrm{CN})_{6}\right]^{3-}\right]} \\
& =E^{\circ \prime}+0.0591 \log \frac{\left[\left[\mathrm{Fe}(\mathrm{CN})_{6}\right]^{3-}\right]}{\left[\left[\mathrm{Fe}(\mathrm{CN})_{6}\right]^{4-}\right]} \quad \text { (V) }
\end{aligned}
$$

\subsection{Measurement of various concentrations of $\mathrm{H}_{2} \mathrm{O}_{2}$ solution}

Figure 5 shows the output in response to the concentration of the $\mathrm{H}_{2} \mathrm{O}_{2}$ solution. The output increased as the final $\mathrm{H}_{2} \mathrm{O}_{2}$ concentration increased and was stable in 8 min after adding each $\mathrm{H}_{2} \mathrm{O}_{2}$ solution for the $\mathrm{H}_{2} \mathrm{O}_{2}$ concentration from 0.01 to $0.1 \mathrm{mM}$. The output fluctuation in 8 min after adding each $\mathrm{H}_{2} \mathrm{O}_{2}$ solution until adding the next $\mathrm{H}_{2} \mathrm{O}_{2}$ solution was only about $2 \mathrm{mV}$. The output rapidly changed for a few seconds ( 5 to $20 \mathrm{~s}$ ) just after adding the $\mathrm{H}_{2} \mathrm{O}_{2}$ solution. The potential stabilization in the range of $0.01-0.1 \mathrm{mM}$ was expected to occur because the enzymatic reaction expressed in Eq. (2) reached the redox equilibrium. The rapid potential change might have occurred by dropping the $\mathrm{H}_{2} \mathrm{O}_{2}$ solution because the value of the potential change was independent of the $\mathrm{H}_{2} \mathrm{O}_{2}$ concentration.

Figure 6 shows the relationship between the $\mathrm{H}_{2} \mathrm{O}_{2}$ concentration and the interfacial potential change of the gold electrode. The interfacial potential change in Fig. 6 was obtained by subtracting $0.0966 \mathrm{~V}$, which corresponds to the potential before $\mathrm{H}_{2} \mathrm{O}_{2}$ addition indicated by the dotted line. The time at which the data was employed is described in Fig. 6. The interfacial potential increased

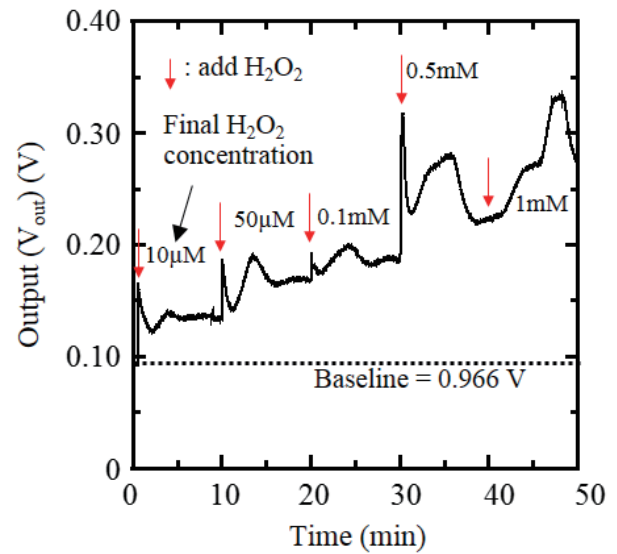

Fig. 5. (Color online) Output $\left(V_{\text {out }}\right)$ in response to changes in $\mathrm{H}_{2} \mathrm{O}_{2}$ concentration. Red arrows indicate the time at which $\mathrm{H}_{2} \mathrm{O}_{2}$ was added. Each final $\mathrm{H}_{2} \mathrm{O}_{2}$ concentration is indicated on the figure.

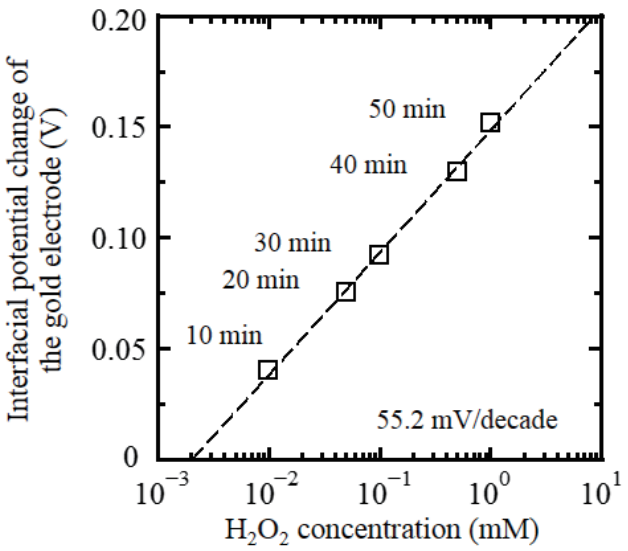

Fig. 6. Relationship between the interfacial potential change of the gold electrode and $\mathrm{H}_{2} \mathrm{O}_{2}$ concentration. 
logarithmically as the $\mathrm{H}_{2} \mathrm{O}_{2}$ concentration increased, and the slope of $55.2 \mathrm{mV} /$ decade was obtained. Therefore, the interfacial potential is expected to change depending on some kind of reaction related to the $\mathrm{H}_{2} \mathrm{O}_{2}$ concentration. However, the estimated value of the slope expressed in Fig. 6 was nearly twice as large as the theoretical value, and the reason why the difference between the two occurred could not be revealed. Further study is necessary to investigate the difference between the two.

\subsection{Measurement of concentration of L-glutamate solutions}

Figure 7 shows the output in response to the concentration of the L-glutamate solution. The output increased as the final L-glutamate concentration increased and was stable in 8 min after adding each L-glutamate solution for the L-glutamate concentration from 0.01 to $0.1 \mathrm{mM}$. The output fluctuation in $8 \mathrm{~min}$ after adding each L-glutamate solution until adding the next L-glutamate solution was only about $0.5 \mathrm{mV}$.

Figure 8 shows the relationship between the L-glutamate concentration and the interfacial potential change. The interfacial potential change in Fig. 8 was obtained by subtracting $0.0724 \mathrm{~V}$, which corresponds to the potential before L-glutamate addition indicated by the dotted line. The time at which the data was employed is described in Fig. 8. The interfacial potential increased logarithmically as the L-glutamate concentration increased, and the value of the slope was expressed in Fig. 8. Because the slope was close to that for the $\mathrm{H}_{2} \mathrm{O}_{2}$ concentration expressed in Fig. 6, the interfacial potential is expected to increase by increasing the $\mathrm{H}_{2} \mathrm{O}_{2}$ concentration. However, the slope of $41.9 \mathrm{mV} /$ decade was lower than that for the $\mathrm{H}_{2} \mathrm{O}_{2}$ concentration. The enzymatic reaction expressed in Eq. (1) may have proceeded insufficiently.

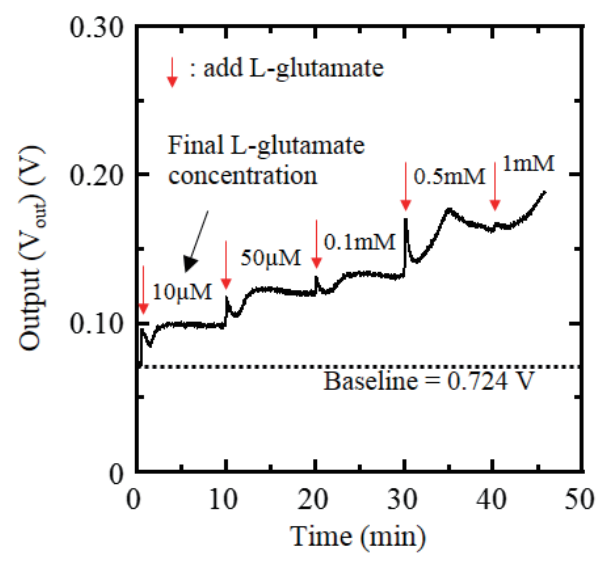

Fig. 7. (Color online) Output $\left(V_{\text {out }}\right)$ in response to changes in glutamate concentration. Red arrows indicate the time at which glutamate was added. Each final glutamate concentration is indicated on the figure.

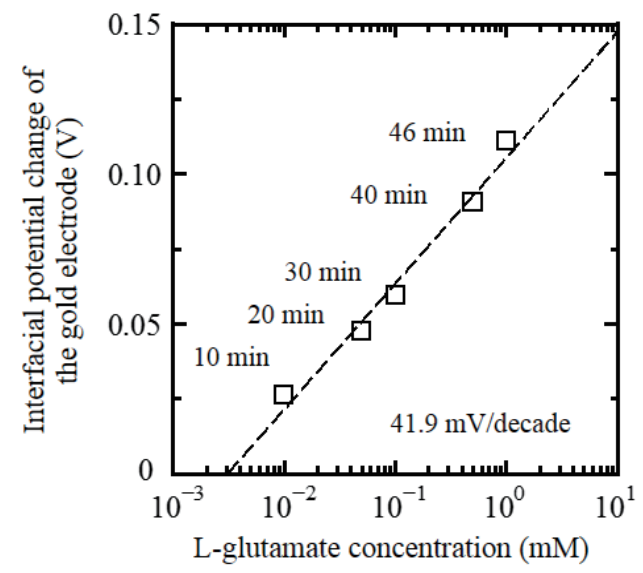

Fig. 8. Relationship between the interfacial potential change of the gold electrode and L-glutamate concentration. 


\section{Conclusions}

An enzyme-based potentiometric glutamate sensor was proposed for neurotransmitter imaging. We showed that the proposed sensor can detect the interfacial potential of the gold electrode, which depends on the logarithmic function from the measurement of the solution of hexacyanoferrate(III) and hexacyanoferrate(II). The sensor showed a response to the L-glutamate concentration in the L-glutamate concentration range of $0.01-1 \mathrm{mM}$ with a sensitivity of $41.9 \mathrm{mV} /$ decade. However, the slope differed from the theoretical value expected from the enzymatic reactions. Therefore, further investigation is necessary to reveal the reason why the difference between the estimated value and the theoretical value occurred.

\section{Acknowledgements}

This work was supported by JSPS KAKENHI Grant Number 24226010, and the CREST, Japan Science and Technology Agency.

\section{References}

1 Y. Okubo, H. Sekiya, S. Namiki, H. Sakamoto, S. Iinuma, M. Yamasaki, M. Watanabe, K. Hirose, and M. Iino: PNAS 107 (2010) 6526.

2 C.-X. Lei, S.-Q. Hu, G.-L. Shen, and R.-Q. Yu: Talanta 59 (2003) 981.

3 A. K. M. Kafi, G. Wu, and A. Chen: Biosens. Bioelectron. 24 (2008) 566.

4 X. Zheng and Z. Guo: Talanta 50 (2000) 1157

5 C.-H. Nieh, Y. Kitazumi, O. Shirai, M. Yamamoto, and K. Kano: Electrochem. Commun. 33 (2013) 135.

6 M. Zhang, C. Mullens, and W. Gorski: Electrochim. Acta 51 (2006) 4528.

7 S. Chakraborty and C. R. Raj: Electrochem. Commun. 9 (2007) 1323.

9 M. I. P. Oliveira, M. C. Pimentel, M. C. B. S. M. Montenegro, A. N. Araújo, M. F. Pimentel, and V. L. da Silva: Anal. Chim. Acta 448 (2001) 207.

8 N. Bakeman, I. M. Isa, N. M. Ali, M. Ahmad, and S. A. Ghani: Int. J. Electrochem. Sci. 7 (2012) 4574.

10 T. Hizawa, K. Sawada, H. Takao, and M. Ishida: Sens. Actuators, B 117 (2006) 509.

11 H. Doi, T. Horio, K. Okumura, T. Hattori, M. Ishida, and K. Sawada: Proc. 18th Int. Conf. Solid-State Sensors, Actuators and Microsystems (Transducers 2015) p. 1751.

12 S. Takenaga, Y. Tamai, K. Hirai, K. Takahashi, T. Sakurai, S. Terakawa, M. Ishida, K. Okumura, and K. Sawada: Proc. 16th Int. Conf. Solid-State Sensors, Actuators and Microsystems (Transducers 2011) p. 954.

13 H. Anan, M. Kamahori, Y. Ishige, and K. Nakazato: Sens. Actuators, B 187 (2013) 254.

14 Y. Ishige, M. Shimoda, and M. Kamahori: Biosens. Bioelectron. 24 (2009) 1096. 